\title{
EDITORIAL
}

\section{The increasing risk of domestic violence, including parricide, during the COVID-19 pandemic: reflections and recommendations}

\author{
Alexandre M. Valença, ${ }^{1,2}$ (iD Lisieux E. Telles, ${ }^{3}$ iD Antônio G. da Silva, ${ }^{4}$ (iD Alcina J. Barros ${ }^{5}$ iD \\ ${ }^{1}$ Instituto de Psiquiatria, Universidade Federal do Rio de Janeiro (UFRJ), Rio de Janeiro, RJ, Brazil. ${ }^{2}$ Departamento de Psiquiatria e Saúde \\ Mental, Universidade Federal Fluminense, Niterói, RJ, Brazil. ${ }^{3}$ Departamento de Psiquiatria e Medicina Legal, Faculdade de Medicina, \\ Universidade Federal do Rio Grande do Sul (UFRGS), Porto Alegre, RS, Brazil. ${ }^{4}$ Faculdade de Medicina, Universidade do Porto, Porto, \\ Portugal. ${ }^{5}$ Programa de Pós-Graduação em Psiquiatria e Ciências do Comportamento, UFRGS, Porto Alegre, RS, Brazil.
}

Domestic violence must be considered one of the serious public health consequences of the COVID-19 pandemic. ${ }^{1}$ In this context, the risk of parricide should be discussed, the extreme rarity of this crime notwithstanding. Parricide consists of the act of killing one's own father (patricide), mother (matricide), foster parents, or adoptive parents. ${ }^{2}$

Abnormal family relationships (which can be extremely severe or overly protective) or psychiatric problems (such as schizophrenia and dependent personality disorder) are more often found in parricides than in other criminal offenders. Evidence suggests that positive symptoms in the context of psychotic illness, such as delusions and hallucinations, ${ }^{3,4}$ are related to violent behavior, and that paranoid delusions were the most common symptom associated with parricide in schizophrenic patients. The risk of this specific crime increases if an underlying psychiatric disorder has not been properly treated. ${ }^{2}$

It is important to stress that the majority of mentally ill patients, including severe cases, are neither dangerous nor a threat to others, and that persons with mental illness are responsible for only a small proportion of violent crimes. ${ }^{5}$ The emergence of negative feelings such as impotence, frustration, and agitation ${ }^{6}$ can lead to aggression and crimes within the household during this pandemic. When a psychotic patient commits a crime, non-adherence with medications, poor insight, and alcohol or drug abuse are usually found, and the victim is commonly a family member. ${ }^{3}$ Since the dynamic interaction of social and contextual factors with clinical variables is an important determinant of violent behavior, ${ }^{5}$ the current global health crisis related to the coronavirus pandemic and its consequences of prolonged home confinement and fewer opportunities for face-to-face psychiatric assessment must be considered.

Brazil has been affected by the COVID-19 pandemic to an alarming extent, with almost 12 million cases and 300,000 deaths as of the time of writing. ${ }^{7}$ People with preexisting psychiatric disorders or substance use problems

Correspondence: Lisieux E. de Borba Telles, Rua Desembargador Moreno Loureiro Lima, 195/1201, Bela Vista, CEP 90450-130, Porto Alegre, RS, Brazil.

E-mail: Itelles@ @cpa.edu.br

Submitted Mar 21 2021, accepted Apr 04 2021, Epub May 102021. are at increased risk for adverse psychosocial outcomes during pandemics. Social distancing, sheltering-in-place, restricted travel, closures of key community establishments, reduced access to mental health services and psychopharmaceuticals, harmful use of alcohol and drugs, and intensification of family conflicts during this crisis may all lead to psychotic outbreaks or worsening of preexisting psychotic symptoms in certain patients, potentially culminating in violent behavior - including parricide. Previous aggressions directed to family members usually occur before parricide, and the aggressor may commonly attempt suicide after the crime, requiring that mental health professionals keep an attentive technical listening and take the necessary measures to protect all the involved ones.

Checking carefully for violent ideation and behavior in high-risk patients is essential, as these have predictive value for conversion to psychosis and likelihood of violence in the future. Patients at elevated risk for violence might benefit from closer monitoring by mental health professionals and rapid-treatment interventions. If faceto-face assessment of the patient is not possible, the mental health team should use all available technological resources, such as teleconsultations or regular phone calls to the patient or his/her reference family.

\section{Disclosure}

The authors report no conflicts of interest.

\section{References}

1 Telles LE, Valença AM, Barros AJ, da Silva AG. Domestic violence in the COVID-19 pandemic: a forensic psychiatric perspective. Braz J Psychiatry. 2021;43:233-4.

2 Lee SY, Lim MH, Lee J, Shim G, Kim Y, Do JA, et al. Minnesota multiphasic personality inventory characteristics of parricide offenders wih schizophrenia in Korea. Psychiatry Investig. 2017;14: 166-71.

How to cite this article: Valença AM, Telles LE, da Silva AG, Barros AJ. The increasing risk of domestic violence, including parricide, during the COVID-19 pandemic: reflections and recommendations. Braz J Psychiatry. 2021;43:572-573. http://dx.doi.org/ 10.1590/1516-4446-2021-1896 
3 Brucato G, Appelbaum PS, Lieberman JA, Wall MM, Feng T, Masucci MD, et al. A longitudinal study of violent behavior in a psychosis-risk cohort. Neuropsychopharmacology. 2018;43: 264-71.

4 de Borba-Telles LE, Goldfeld PR, Barros AJ, Schwengber HE, PeresDay V, de Moraes-Costa G. Is parricide a stable phenomenon? An analysis of parricide offenders in a forensic hospital. Rev Fac Med. 2017;65:9-13.
5 Varshney M, Mahapatra A, Krishnan V, Gupta R, Deb KS. Violence and mental illness: what is the true story. J Epidemiol Community Health. 2016;70:223-5.

6 Mazza M, Marano G, Lai C, Janiri L, Sani G. Danger in danger: interpersonal violence during COVID-19 quarantine. Psychiatry Res. 2020;289:113046.

7 Worldometer. Coronavirus population [Internet]. [cited 2021 Mar 21]. www.worldometers.info/coronavirus/country/brazil/ 